\title{
PENGEMBANGAN LEMBAGA PENGELOLA DANA BERGULIR SYARIAH DALAM MENDUKUNG USAHA MIKRO KECIL DAN MENENGAH DI INDONESIA
}

\section{DEVELOPMENT OF REVOLVING FUND MANAGEMENT INSTITUTION SHARIA IN SUPPORTING MICRO SMALL AND MEDIUM ENTERPRISES IN INDONESIA}

\author{
A.S. Rusydiana1a; T. Nugraha²; \\ 1aPeneliti pada Shariah Economic Applied Research and Training (SMART) Indonesia \\ dan Dosen Sekolah Tinggi Ekonomi Islam Tazkia Bogor, \\ e-mail: aamsmart@gmail.com \\ 2Universitas Airlangga Surabaya, Jl. Airlangga No.4 - 6, Airlangga, Gubeng, Kota SBY, \\ Jawa Timur 60115
}

\begin{abstract}
This study attempts to identify the factors of needs, activities and objectives in the development of revolving fund management institution (LPDB) sharia in Indonesia, using the Interpretative Structural Model (ISM) approach. The results of this study provide some conclusions include: (1) Elements of the needs of the key in LPDB sharia development strategy in Indonesia to improve SMEs is the need for strong support on internal condition of the institution; (2) Elements of activities that are key to LPDB Shariah development are to identify the problem faced by the member in the field and give some solutions, and (3) Elements of problem that maybe faced in LPDB sharia development in Indonesia is the changes on technology in business lanscape and economic, overall.
\end{abstract}

Keywords: LPDB, Small micro enterprises, Interpretative Structural Model (ISM)

\begin{abstract}
ABSTRAK
Penelitian ini berupaya untuk mengidentifikasi faktor-faktor kebutuhan, perubahan, dan sasaran dalam pengembangan lembaga pengelola dana bergulir (LPDB) syariah di Indonesia dengan menggunakan pendekatan Interpretative Structural Model (ISM). Hasil penelitian ini memberikan beberapa kesimpulan antara lain: (1) Elemen kebutuhan yang menjadi kunci utama dalam strategi pengembangan LPDB syariah di Indonesia untuk meningkatkan UMKM adalah perlu adanya dukungan yang kuat pada kondisi internal lembaga; (2) Elemen perubahan yang merupakan kunci utama dalam pengembangan LPDB syariah adalah untuk mengidentifikasi masalah yang dihadapi oleh anggota di lapangan dan memberikan beberapa solusi; dan (3) Elemen masalah yang mungkin dihadapi dalam pengembangan LPDB syariah di Indonesia adalah perubahan teknologi dalam struktur ekonomi dan bisnis secara umum.
\end{abstract}


Kata Kunci: LPDB, Usaha Kecil Mikro, Interpretative Structural Model (ISM)

Rusydiana, Aam Slamet. 2018. Pengembangan LPDB Syariah dalam Mendukung Usaha Mikro Kecil dan Menengah di Indonesia. Jurnal Syarikah 4 (2): 130-144.

\section{PENDAHULUAN}

Usaha Mikro, Kecil dan Menengah (UMKM) merupakan usaha produktif yang dimiliki oleh perseorangan ataupun Badan Usaha yang sudah memasuki kriteria Usaha Mikro. Di Indonesia sendiri, keberadaan UMKM memiliki peran andil yang cukup besar pada perekonomian nasional. Pada tahun 2015, Bank Indonesia merilis pada laporan profil UMKM yang menjelaskan bahwa UMKM mempunyai tingkat penyerapan tenaga kerja sekitar 97 persen dari seluruh tenaga kerja Nasioal dan memiliki kontribusi pada PDB sekitar 57 persen (Bank Indonesia 2015). Namun demikian, permasalahan pembiayaan dan pengembangan usaha masih menjadi permasalahan klasik yang terjadi pada UMKM.

Melihat fenomena diatas, bantuan dan pengembangan UMKM sangat diperlukan. Oleh karena itu sebagai bentuk dukungan dalam mengakselerasi pembiayaan pada UMKM khususnya pada pembiayaan berpola syariah. Pemerintah selaku regulator telah menerbitkan Peraturan Menteri Negara Koperasi dan UKM Republik Indonesia Nomor: 22/Kep/M.KUKM/VII/2017, tentang Pengangkatan Direktur Pembiayaan Syariah pada LPDB-KUMKM. Lembaga Pengelola Dana Bergulir (LPDB) merupakan sebuah lembaga yang dibentuk oleh Kementerian Koperasi dan
UKM yang bertujuan untuk membantu para Usaha Mikro Kecil dan Menengah dalam permasalahan permodalan. Bantuan yang diberikan oleh LPDB kepada para UMKM bisa dalam bentuk pembiayaan ataupun pinjaman yang disesuaikan dengan kebutuhan para UMKM (Berita Negara Republik Indonesia 2017).

Keberadaaan

Direktorat

Pembiayaan Syariah LPDB-KUMKM dalam membantu para UMKM dengan pola pembiayaan syariah sendiri merupakan tuntutan atas kebutuhan para pengusaha UMKM khususnya bagi para Muslim. Hal ini dapat membantu para pengusaha untuk mendapat bantuan permodalan dan pengembangan usaha tanpa harus menggunakan sistem bunga atau riba. Jika dilihat dari konsepsinya, LPDB-KUMKM merupakan salah satu bentuk Lembaga Keuangan Mikro Syariah yang eksistensinya sangat dibutuhkan para pengusaha mikro. Namun, disisi lain pada praktik di lapangannya, pengembangan peran LPDB-KUMKM sebagai bagian dari LKMS masih banyak mengalami kendala dan tantangan baik dari sisi internal ataupun eksternal. Selain itu jika dilihat dari perbandingan jumlah Rencana Anggaan Biaya, Dana pembiayaan Syariah memiliki porsi lebih kecil sebesar 450.000.000.000 daripada konvensional yang sebesar 750.000.000.000 (LPDB-KUKM 2018). Hal ini menunjukkan bahwa masih 
perlunya akselerasi program pembiayaan syariah. Oleh karena itu, dalam rangka mewujudkan visi LPDB-KUMKM sebagai lembaga yang dapat diandalkan dalam memberikan layanan pinjaman atau pembiayaan kepada UMKM. Serta menjadi integrator dan pemercepat industri keuangan mikro daerah yang berbasis syariah. Maka perlu dibentuk model pengelolaan yang efektif dan tepat sasaran. Hal ini juga melihat dari usia LPDB-KUMKM yang bergerak di pembiayaan syariah yang masih tergolong muda.

Dengan pendekatan Interpretive Structural Model berbasis hubungan VAXO yang dikembangkan Saxena (1992), penelitian ini mencoba mencari model pengelolaan LPDB efektif untuk pengembangan UKM dan UMK syariah di Indonesia, termasuk di dalamnya aspek pendukung kinerja, masalah, strategi dan lembaga yang berperan dalam pengembangaan UKM dan UMK syariah di Indonesia.

\section{MATERI DAN METODE}

Lembaga keuangan mikro merupakan salah satu lembaga keuangan yang didirikan untuk masyarakat mikro. Adanya lembaga keuangan mikro ini dapat membantu masyarakat dalam pengembangan usahanya. Menurut undang-undang No.1 tahun 2013 Lembaga keuangan Mikro merupakan sebuah lembaga keuangan yang khusus didirikan untuk masyarakat mikro dengan memberikan jasa untuk dilakukan pengembangan usaha dan adanya pemberdayaan masyarakat. Jasa yang diberikan ini dilakukan melalui pembiayaan atau pinjaman yang diberikan kepada anggota lembaga keuangan mikro tersebut maupun kepada masyarakat yang membutuhkan dana sebagai pengembangan usahanya dan sebagai dana untuk memulai usahanya, adanya pengelolaan simpaan. Selain itu juga, adanya pemberian jasa konsultasi untuk pengembangan usaha yang dilakukan tidak hanya untuk mengejar keuntungan. (Baskara 2013)

Sedangkan Lembaga keuangan Mikro Syariah (LKMS) adalah lembaga keuangan mikro yang pada praktiknya menerapkan prinsip syariah. LKMS ini terdiri dari berbagai lembaga diantaranya BPRS, BMT, Koperasi Syariah serta lembaga keuangan syariah lainnya yang diatur pada Peraturan Ototritas Jasa Keuangan (OJK) Nomor 12/P0JK.05/ 2014 tentang Perizinan Usaha dan Kelembagaan Keuangan Mikro. Dalam peratuan ini, telah diatur mengenai bentuk badan hukum LKM, yakni perseroan terbatas dan koperasi.

Menurut Aslichan et.al (2009) terdapat perbedaan mendasar antara LKM konvensional dengan LKM Syariah yaitu: 1) LKM Syariah menerapkan sistem bagi hasil dengan nasabahnya dan tidak menerapkan segala bentuk transaksi pinjam meminjam uang yang dikenakan bunga; 2) hubungan partisipasi dalam menanggung resiko dan menerima hasil dari suatu perjanjian bisnis merupakan hubungan antara LKM Syariah dengan nasabahnya tidak berdasarkan hubungan debitur-kreditur; 3) LKM Syariah memisahkan kedua jenis pendanaan supaya dapat dibedakan antara hasil yang diperoleh dari dana sendiri dengan hasil yang diperoleh dari dana simpanan yang diterimanya atas dasar prinsip bagi hasil; 4) LKM Syariah memberikan layanan atas 
dasar kemitraan seperti mudharabah dan musyarakah, atas dasar jual beli atau atas dasar sewa (ijarah) dan tidak memberikan layanan pinjaman dengan bunga dalam bentuk uang tunai.

Lembaga pengelola dana bergulir koperasi dan usaha mikro, kecil dan menengah (LPDB-KUKM) merupakan satuan kerja yang dibentuk oleh Kementerian Koperasi dan UKM yang menerapkan sistem pengelolaan keuangan Badan Layanan Umum (BLU), yang mempunyai tugas utama dalam pengelolaan dana bergulir, antara lain (Kemas: 2015):

1. Melakukan penghimpunan, peralihan dan pengembalian dana bergulir yang berasal dari pinjaman program dana bergulir Kementerian Koperasi dan UKM, dan penyaluran pinjaman/pembiayaan yang telah dijalankan LPDB-KUMKM

2. Melakukan pemberian pinjaman/pembiayaan kepada koperasi, dana Ussaha Mikro, Kecil dana Menengah (KUMKM) dengan atau tanpa lembaga perantara, baik Lembaga Keuangan Bank (LKB), maupun Lembaga Keuangan Non Bank (LKNB).

3. Melakukan pemberian bentuk pembiayaan lainnya bagi KUMKM sesuai dengan kebutuhan KUMKM.

\section{Metodologi Penelitian}

Data yang digunakan dalam penelitian ini merupakan data primer yang diperoleh dari hasil wawancara dengan pakar dan praktisi yang berjumlah 7 (Tujuh) orang, kuesioner yang disebarkan kepada responden yang ada didalamnya, dan studi literatur yang berhubungan dengan masalah-masalah yang dihadapi dalam pengembangan
LPDB Syariah di Indonesia untuk meningkatkan UMKM.

Beberapa sub-elemen strategi pengembangan LPDB Syariah di Indonesia untuk meningkatkan UMKM diperoleh dari studi pustaka dan diskusi. Strategi-strategi tersebut akan dituangkan dalam bentuk kuesioner dengan menggunakan pendekatan Interpretative Structural Modelling (ISM), mengikuti Saxena dengan sembilan elemen yakni kebutuhan, kendala atau permasalahan, perubahan yang dimungkinkan, tujuan, tolak ukur keberhasilan, kegiatan/aktivitas, pelaku, segmen masyarakat yang terpengaruh, dan ukuran efektivitas.

Interpretative Structural Modeling (ISM) merupakan teknik pemodelan yang dikembangkan untuk perencanaan kebijakan strategi (Marimin: 2004). ISM diciptakan pertama kali oleh J. Warfield pada tahun 1973, dimana Warfield mendefinisikan ISM sebagai proses belajar dengan bantuan komputer yang memungkinkan individu-individu atau kelompok untuk mengembangkan peta hubungan yang kompleks antara berbagai elemen yang terlibat dalam situasi yang kompleks.

Interpretive Structural Modelling (ISM) sebagaimana diaplikasikan oleh Bhattacharya dan Momaya (2009), adalah metodologi perencanaan interaktif canggih yang memungkinkan sekelompok orang, bekerja sebagai tim, untuk mengembangkan struktur yang mendefinisikan hubungan di antara unsur-unsur dalam suatu himpunan. Struktur diperoleh dengan menjawab pertanyaan sederhana. Unsur yang akan terstruktur (seperti tujuan, hambatan, masalah, dan sebagainya) yang 
ditentukan oleh kelompok pada awal sesi perencanaan ISM. Proses ISM dimulai dari permodelan sistem dan diakhiri dengan validasi model. Melalui teknik ISM, model mental yang tidak jelas ditransformasikan menjadi model sistem yang tampak (visible).

ISM merupakan metode dalam pengambilan keputusan dari situasi yang kompleks dengan menghubungkan dan mengorganisasi ide dalam peta map visual. Dalam hal pengambilan keputusan, ISM ada sedikit kesamaan dengan metode Analytic Network Process (ANP) yang dikembangkan Thomas L. Saaty. Misal, penelitian yang dilakukan oleh Rusydiana \& Devi (2013b). Ide dasarnya adalah menggunakan ahli yang berpengalaman dan pengetahuan praktis untuk menguraikan sistem yang rumit menjadi beberapa sub-sistem (elemen) dan membangun sebuah model struktural bertingkat. ISM sering digunakan untuk memberikan pemahaman dasar situasi yang kompleks, serta menyusun tindakan untuk memecahkan masalah (Gorvett and Liu, 2007).

Dalam pelaksanaan metode ISM terlebih dahulu dilakukan diskusi dengan para pakar (brainstorming) untuk menjaring ide-ide pengembangan organisasi yang terdiri dari orang-orang yang memahami konsep ISM, mengerti masalah pengembangan model pengembangan LPDB syariah, memiliki keahlian di bidang microfinance dan empowerment. Dari diskusi mengenai strategi pengembangan tersebut diperoleh beberapa ide atau variabel yang akan diolah menggunakan ISM.

Langkah pertama dalam pengolahan ISM adalah membuat Structural Self Interaction Matrix (SSIM), dimana variabel-variabel tersebut dibuat hubungan konstektualnya dengan menjadikan satu variabel $i$ dan variabel $j$. Selanjutnya adalah membuat reachibility matrix (RM) dengan mengubah $\mathrm{V}, \mathrm{A}, \mathrm{X}$ dan 0 dengan bilangan 1 dan 0 . Langkah terakhir adalah membuat Canonical Matrix untuk menentukan level melalui iterasi. Setelah tidak ada lagi irisan (intersection), selanjutnya dibuat model yang dihasilkan oleh ISM yang merupakan suatu model untuk memecahkan masalah, dalam hal ini pengembangan model LPDB syariah. Dari model tersebut kemudian nantinya akan dibuat suatu road map pengembangan lembaga (level).

Ada beberapa penelitian yang telah dilakukan dengan menggunakan metode ISM. Beberapa diantaranya adalah yang dilakukan oleh Ascarya et.al (2012) terkait pengembangan bank syariah, Devi dan Rusydiana (2016) tentang pinjaman berbasis kelompok, Rusydiana (2018a, 2018b), Rusydiana dan Devi (2018), Bolanos et.al (2005), dan Kanungo \& Batnagar (2002) untuk aplikasi industri lain. Sementara itu penelitian dengan metode ISM yang sifatnya lebih teoretis telah dilakukan oleh Lee (2007) dan Takkar et.al (2007).

\section{Hubungan Antarelemen dalam ISM}

Menurut Marimin (2004) proses metode ISM adalah dilakukan perhitungan menurut Aturan Transivity dimana dilakukan koreksi terhadap SSIM sampai terjadi matriks yang tertutup. Modifikasi SSIM membutuhkan masukan dari para panelis/pakar, dengan diberi catatan khusus agar perhatian ditunjukan hanya pada sub-elemen tertentu. Hasil revisi SSIM dan matriks yang memenuhi syarat Aturan Transivity diperoses lebih 
lanjut. Untuk revisi dapat juga dilakukan transformasi matriks dengan program komputer.

Aturan Transivity merupakan aturan kelengkapan dari lingkaran sebab akibat (casual-loop), sebagai misal: A mempengaruhi $B$ dan $B$ mempengaruhi C, maka A (seharusnya) mempengaruhi C. Jika D meningkatkan $\mathrm{E}$ dan $\mathrm{E}$ meningkatkan $\mathrm{F}$, maka $\mathrm{D}$ (tidak seharusnya) memperkecil F.

Tabel 1. Keterkaitan Antar Sub-elemen pada Teknik ISM

\begin{tabular}{|l|l|l|}
\hline No. & Jenis & Interprestasi \\
\hline 1. & $\begin{array}{l}\text { Pembandingan } \\
\text { (Coperative })\end{array}$ & $\begin{array}{l}\text {. A lebih } \\
\text { penting/besar/indah, } \\
\text { daripada B }\end{array}$ \\
\hline 2. & $\begin{array}{l}\text { Peryataan } \\
\text { (Definitive })\end{array}$ & $\begin{array}{l}\text {.A adalah atribut B } \\
\text {.A termasuk didalam B } \\
\text {.A mengartikan B }\end{array}$ \\
\hline 3. & $\begin{array}{l}\text { Pengaruh } \\
\text { (Influence })\end{array}$ & $\begin{array}{l}\text {.A menyebabkan B } \\
\text {.A adalah debagia } \\
\text { penyebab B } \\
\text {.A mengembangkan B } \\
\text {.A menggerakan B } \\
\text {.A meningkatkan B }\end{array}$ \\
\hline 4. & $\begin{array}{l}\text { Ruang (Spiral) } \\
\text {.A adalah selatan/ } \\
\text { utara B } \\
\text {.A diatas B } \\
\text {.A sebelah kiri B }\end{array}$ \\
\hline 5. & $\begin{array}{l}\text { Waktu } \\
\text { (Temporate/Time } \\
\text { Scale) }\end{array}$ & $\begin{array}{l}\text { A mendahului B } \\
\text { A mengikuti B } \\
\text {.A mempunyai } \\
\text { prioritas lebih dari B }\end{array}$ \\
\hline
\end{tabular}

Pengolahan lebih lanjut dari Reachability Matrix yang telah memenuhi Aturan Transivity adalah penetapan pilihan jenjang (level partition). Pengolahan bersifat tabulatif dengan pengisisan format, dan bisa dibantu dengan komputer. Berdasarkan pilihan jenjang maka dapatlah digambarkan skema setiap elemen menurut jenjang vertikal maupun horisontal. Untuk beragam sub-elemen dalam suatu elemen berdasar RM disusunlah Driver-PowerDependence. Klasifikasi sub-elemen dipaparkan dalam 4 sektor berikut (Marimin, 2004):

Sektor 1 : Weak driver-weak dependent variables (AUTONOMOUS). Perubahan disektor ini umumnya tidak berkaitan dengan sistem, dan mungkin memeiliki hubungan kecil, meskipun hubungan bisa saja kuat.

Sektor 2 : Weak driver-strongly dependent variables (DEPENDENT). Umumnya perubahan disisni tidak bebas.

Sektor 3 : Strong driver-strongly dependent variables (LINKAGE). Peubah pada sektor ini harus dikaji secara hatihati sebab hubungan antar peubah adalah tidak stabil. Setiap tindakan pada peubah tersebuat akan memeberikan dapak terhadap lainnya dan umpan balik pengaruhnya bisa memperbesar dampak.

Sektor 4 : Strong drive weak dependent variables (INDEPENDENT). Peubah pada sektor ini merupakan bagian sisa dari sistem dan disebut peubah bebas.

Dalam keseluruhan proses teknik ISM maka berbagai urutan kerja dari tahap penyusunan hierarki sampai hasil analisis dapat dibuat. Berbagai macam bentuk struktur model dapat dibangkitkan dalam ISM. Berdasarkan pengalaman empirik dalam menyusun sub-elemen dari suatu elemen tertentu, awalnya diperlukan daftar selengkap mungkin (exhausted list). Setelah itu dilakukan pengurangan dengan prinsip eliminasi sub-elemen yang tidak begitu penting; dan atau menyatukan dua atau tiga sub-elemen. 


\section{HASIL DAN PEMBAHASAN}

Berdasarkan identifikasi masalah, strategi, dan hal-hal yang berkaitan dengan pengembangan LPDB syariah di Indonesia, kemudian dibangunlah model kerangka ISM untuk beberapa tujuan yang diinginkan, dalam hal ini terkait aspek masalah atau tantangan yang dihadapi, strategi pengembangan dan stakeholder yang berkepentingan dalam pengembangan LPDB syariah di Indonesia. Untuk membangun hubungan kontekstual antarvariabel dalam model, metode ISM menggunakan opini dari para pakar dengan kerangka VAXO. Kaitannya dengan penelitian ini, sekelompok grup pakar dilibatkan dalam menyusun model yang terdiri dari akademisi dan praktisi keuangan mikro dan UMKM.

Untuk membangun sebuah model, peneliti memutuskan untuk mengikuti metode tradisional yang lazim digunakan melalui brainstorming berikut wawancara mendalam atau indepth interview dengan para pakar dimaksud, untuk kemudian menerima masukan dan merevisi model secara berkala. Beberapa literatur dan studi terkait pengembangan model LPDB juga didiskusikan dengan para pakar untuk memvalidasi dan membuat sempurna model.

Untuk menganalisis hubungan antarvariabel atau antar enabler dari pengembangan LPDB syariah dari masing-masing kelompok tujuan, hubungan kontekstual dipilih dengan mendefinisikan bagaimana pengaruh satu variabel terhadap variabel lain: apakah mempengaruhi, dipengaruhi, saling mempengaruhi atau tidak ada hubungan sama sekali. Dari dasar ini, hubungan konstekstual antarvariabel dibangun.
Para pakar kemudian ditanya dan diminta justifikasi dalam format kuesioner untuk membandingkan pernyataan dalam kolom dengan baris untuk masing-masing kotak pertanyaan dengan memilih nilai antara $\mathrm{V}, \mathrm{A}, \mathrm{X}$ atau $\mathrm{O}$, untuk merepresentasikan persepsi mereka atas hubungan antara variabel tersebut.

\section{Structural Self-Interaction Matrix (SSIM)}

Tampak dalam tabel di bawah, terdapat tujuh variabel terkait aspek pengembangan LPDB syariah di Indonesia yang disusun dalam format baris dan kolom. Variabel dalam baris dan kolom direpresentasikan masing-masing dengan huruf i dan j. Dengan demikian, setiap pasangan variabel dianalisis secara terpisah setelah pembentukan grid, yang diperoleh dalam proses di atas. Empat kata kunci digunakan untuk mewakili arah hubungan antara satu set variabel (i dan j), dimana:

(a) $\mathrm{V}$ mengindikasikan bahwa variabel i mempengaruhi variabel j;

(b) A mengindikasikan bahwa variabel $\mathrm{j}$ mempengaruhi variabel i;

(c) X mengindikasikan bahwa variabel i mempengaruhi variabel $j$ dan sebaliknya variabel j mempengaruhi variabel i, atau dengan arti lain terdapat hubungan saling mempengaruhi antara variabel i dan j; (d) 0 mengindikasikan bahwa variabel i dan $\mathrm{j}$ tidak saling berhubungan.

Hubungan antarvariabel dalam model direpresentasikan dalam sebuah matriks yang disebut sebagai structural self interaction matrix (SSIM), dengan nilai untuk setiap pasangan variabel menjadi nilai yang disepakati di antara para pakar. 
Tabel 2. Structural Self Interaction Matrix (SSIM)

\begin{tabular}{|c|c|c|c|c|c|c|c|}
\hline No & $\begin{array}{c}\text { Deskripsi } \\
\text { Variabel }\end{array}$ & 7 & 6 & 5 & 4 & 3 & 2 \\
\hline A1 & $\begin{array}{l}\text { Kondisi } \\
\text { internal }\end{array}$ & V & A & $X$ & 0 & $V$ & A \\
\hline A2 & $\begin{array}{l}\text { Kondisi } \\
\text { eksternal }\end{array}$ & A & V & A & V & 0 & \\
\hline A3 & $\begin{array}{l}\text { Dampak \& } \\
\text { manfaat } \\
\text { penyaluran } \\
\text { dana } \\
\text { bergulir }\end{array}$ & $\mathrm{V}$ & $\mathrm{X}$ & $\mathrm{X}$ & 0 & & \\
\hline $\mathrm{A} 4$ & $\begin{array}{l}\text { Penyerapan } \\
\text { tenaga kerja }\end{array}$ & $X$ & A & $\mathrm{X}$ & & & \\
\hline A5 & $\begin{array}{l}\text { Standardisa } \\
\text { si } \\
\text { pelayanan } \\
\text { kepada } \\
\text { (calon) } \\
\text { mitra }\end{array}$ & $X$ & V & & & & \\
\hline A6 & $\begin{array}{l}\text { Evaluasi } \\
\text { keberhasila } \\
\text { n program }\end{array}$ & A & & & & & \\
\hline A7 & $\begin{array}{l}\text { Pengukuran } \\
\text { kepuasan } \\
\text { mitra }\end{array}$ & & & & & & \\
\hline
\end{tabular}

Catatan: Entri dalam tabel: V ketika baris mempengaruhi kolom; A ketika kolom mempengaruhi baris; $\mathrm{X}$ ketika baris dan kolom saling mempengaruhi; dan 0 ketika tidak ada hubungan antara baris dan kolom.

\section{Reachibility Matrix}

Reachibility matrix diperoleh dari structural self interaction matrix (SSIM) dengan menggunakan proses dua langkah. Pada langkah pertama, abjad yang digunakan untuk menunjukkan hubungan antarvariabel dalam SSIM diganti dengan "0" atau "1". Nilai dalam reachibility matrix tergantung pada jenis hubungan dalam SSIM (Faisal, 2015) dan dirangkum dalam hubungan berikut ini:

(1) Jika hubungan antara variabel dalam satu baris dengan variabel lain dalam kolom adalah "V", maka dalam matriks reachibility awal, entri baris menjadi "1" sementara entri kolom antara dua variabel ini menjadi "0";

(2) Jika hubungan antara variabel dalam satu baris dengan variabel lain dalam kolom adalah "A", maka dalam matriks reachibility awal, entri baris menjadi "0" sementara entri kolom antara dua variabel ini menjadi "1";

(3) Jika hubungan antara variabel dalam satu baris dengan variabel lain dalam kolom adalah "X", maka dalam matriks reachibility awal, entri baris menjadi "1" sementara entri kolom antara dua variabel ini menjadi "1";

(4) Jika hubungan antara variabel dalam satu baris dengan variabel lain dalam kolom adalah "0", maka dalam matriks reachibility awal, entri baris menjadi "0" sementara entri kolom antara dua variabel ini menjadi "0".

Berdasarkan aturan di atas, matriks reachibility awal untuk enabler aspek pengembangan LPDB syariah dibangun. Selanjutnya, dengan memasukkan konsep transitivitas (Ravi, 2015), matriks reachibility akhir diperoleh. Transitivitas dalam hubungan kontekstual adalah asumsi dasar yang dibuat dalam ISM. Konsep ini menyatakan bahwa jika variabel $X$ terkait dengan $Y$ dan Y terkait dengan $\mathrm{Z}$, maka $\mathrm{X}$ harus terkait dengan $\mathrm{Z}$ (Venkatesh et.al, 2015; Jabeen et.al, 2017). Matriks reachibility juga menyediakan 'driving power' (kekuatan mempengaruhi) dan 'dependence power' dari setiap enabler. Dengan demikian, dalam tabel matriks reachibility terakhir, driving power untuk A1 (Kondisi internal) adalah jumlah total nilai-nilai entri dalam baris, yaitu 7. Sementara itu, nilai 'dependence power' untuk A1 (jumlah dari entri dalam kolom) adalah 4. Demikian pula, nilai-nilai 'driving power' dan 'dependence power' dihitung untuk semua enablers yang tersisa. 
Tabel 3. Final Reachibility Matrix (RM)

\begin{tabular}{|c|c|c|c|c|c|c|c|c|c|}
\hline No & $\begin{array}{c}\text { Deskripsi } \\
\text { Variabel }\end{array}$ & 1 & 2 & 3 & 4 & 5 & 6 & 7 & $\begin{array}{c}\text { Drivi } \\
\text { ng } \\
\text { pow } \\
\text { er }\end{array}$ \\
\hline A1 & $\begin{array}{l}\text { Kondisi } \\
\text { internal }\end{array}$ & 1 & 1 & 1 & 1 & 1 & 1 & 1 & 7 \\
\hline A2 & $\begin{array}{l}\text { Kondisi } \\
\text { eksternal }\end{array}$ & 1 & 1 & 1 & 1 & 1 & 1 & 1 & 7 \\
\hline A3 & $\begin{array}{l}\text { Dampak\& } \\
\text { manfaat } \\
\text { penyalura } \\
\text { n dana } \\
\text { bergulir }\end{array}$ & 1 & 1 & 1 & 1 & 1 & 1 & 1 & 7 \\
\hline A4 & $\begin{array}{l}\text { Penyerapa } \\
\mathrm{n} \text { tenaga } \\
\text { kerja }\end{array}$ & 0 & 0 & 0 & 1 & 0 & 1 & 0 & 2 \\
\hline A5 & $\begin{array}{l}\text { Standardis } \\
\text { asi } \\
\text { pelayanan } \\
\text { kepada } \\
\text { mitra }\end{array}$ & 1 & 1 & 1 & 1 & 1 & 1 & 1 & 7 \\
\hline A6 & $\begin{array}{l}\text { Evaluasi } \\
\text { keberhasil } \\
\text { an } \\
\text { program }\end{array}$ & 0 & 0 & 0 & 0 & 0 & 1 & 0 & 1 \\
\hline \multirow[t]{2}{*}{ A7 } & $\begin{array}{l}\text { Pengukura } \\
\mathrm{n} \\
\text { kepuasan } \\
\text { mitra }\end{array}$ & 0 & 0 & 0 & 0 & 0 & 1 & 1 & 2 \\
\hline & $\begin{array}{l}\text { Dependen } \\
\text { ce Power }\end{array}$ & 4 & 4 & 4 & 5 & 4 & 7 & 5 & \\
\hline
\end{tabular}

Dari matriks reachibility akhir, langkah selanjutnya adalah membangun 'reachibility set' dan 'antecedent set'. Jangkauan yang ditetapkan untuk enabler tertentu terdiri dari enabler itu sendiri dan enabler lain yang dapat membantu mencapainya. Demikian pula, set anteseden terdiri dari enabler itu sendiri dan enabler lain yang mempengaruhinya. Perpotongan set ini diturunkan untuk semua enablers. Enabler yang mana set persimpangan dan reachibility adalah sama, membentuk level teratas dari hirarki dalam model ISM. Enabler ini tidak akan membantu mencapai enabler lain di atas tingkat mereka (Jabeen dan Faisal, 2018). Tingkat yang diidentifikasi membantu dalam membangun kuadran dan model akhir ISM.

\section{Analisis Kuadran MICMAC}

Dalam penelitiannya, Godet (1986) telah mempopulerkan matriks perkalian dampak silang atau 'matrix of cross impact multiplications applied to classification' (MICMAC) untuk mengklasifikasikan variabel sistem yang diteliti. Dasar dari klasifikasi ini adalah 'driving power' dan 'dependence power' yang dihitung dalam matriks reachibility akhir. Selain itu, analisis MICMAC dapat digunakan untuk memeriksa hubungan langsung dan laten di antara enabler yang diperoleh dari teknik ISM. Jadi, berdasarkan 'driving power' dan 'dependence power', enabler dalam penelitian ini diklasifikasikan ke dalam empat kelompok, seperti yang ditunjukkan dan dijelaskan berikut ini:

(1) Variabel Autonomous: Variabelvariabel ini tidak memiliki daya pengaruh yang tinggi atau ketergantungan yang tinggi. Mereka terlepas dari sistem, dimana mereka memiliki beberapa tautan yang mungkin sangat kuat. Kuadran I mewakili variabel otonom (autonomous). Dalam penelitian ini, dampak dan manfaat penyaluran dana bergulir termasuk dalam kategori ini.

(2) Variabel Dependent: Kuadran II merupakan variabel dependen yang memiliki kekuatan mempengaruhi rendah dan ketergantungan tinggi. Dari analisis MICMAC, enabler 1 dan 2 adalah variabel dependen. Variabel dependen adalah kondisi internal dan eksternal.

(3) Variabel Linkage: Variabel-variabel ini memiliki daya pengaruh yang tinggi sekaligus ketergantungan yang tinggi pula. Karakteristiknya adalah bahwa setiap tindakan pada mereka akan memiliki efek pada variabel di atas tingkat mereka dan efek umpan balik pada diri mereka sendiri. Kuadran III merupakan variabel linkage. Dalam 
penelitian ini, enabler 5,6 dan 7 termasuk dalam kategori variabel linkage. Standardisasi pelayanan kepada mitra, evaluasi keberhasilan dan pengukuran kepuasan mitra termasuk dalam variabel linkage ini.

(4) Variabel Independent: Variabelvariabel ini memiliki daya mempengaruhi yang tinggi dan ketergantungan yang rendah. Mereka mewakili Kuadran IV. Dalam penelitian ini, enabler 4 yaitu penyerapan tenaga kerja, termasuk dalam kategori ini.

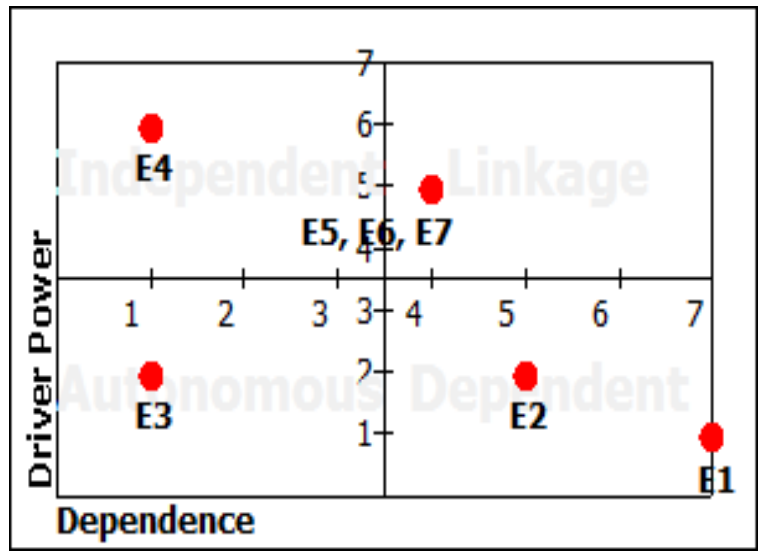

Gambar 1. Analisis MICMAC Aspek Pengembangan LPDB Syariah

\section{Elemen Aspek Kebutuhan}

Elemen aspek kebutuhan dalam strategi pengembangan LPDB Syariah di Indonesia untuk meningkatkan UMKM dijabarkan dalam 7 (tujuh) sub-elemen sebagai berikut: (A1) Kondisi internal LPDB, (A2) Kondisi eksternal, (A3) Dampak dan manfaat penyaluran dana bergulir, (A4) Penyerapan tenaga kerja, (A5) Standardisasi pelayanan kepada mitra dan calon mitra, (A6) Evaluasi keberhasilan program pembiayaan dana bergulir, (A7) Pengukuran kepuasan para mitra. Hasil dari pengolahan ISM untuk elemen aspek kebutuhan pengembangan
LPDB Syariah dapat dilihat dibawah ini, dengan rincian sebagai berikut:

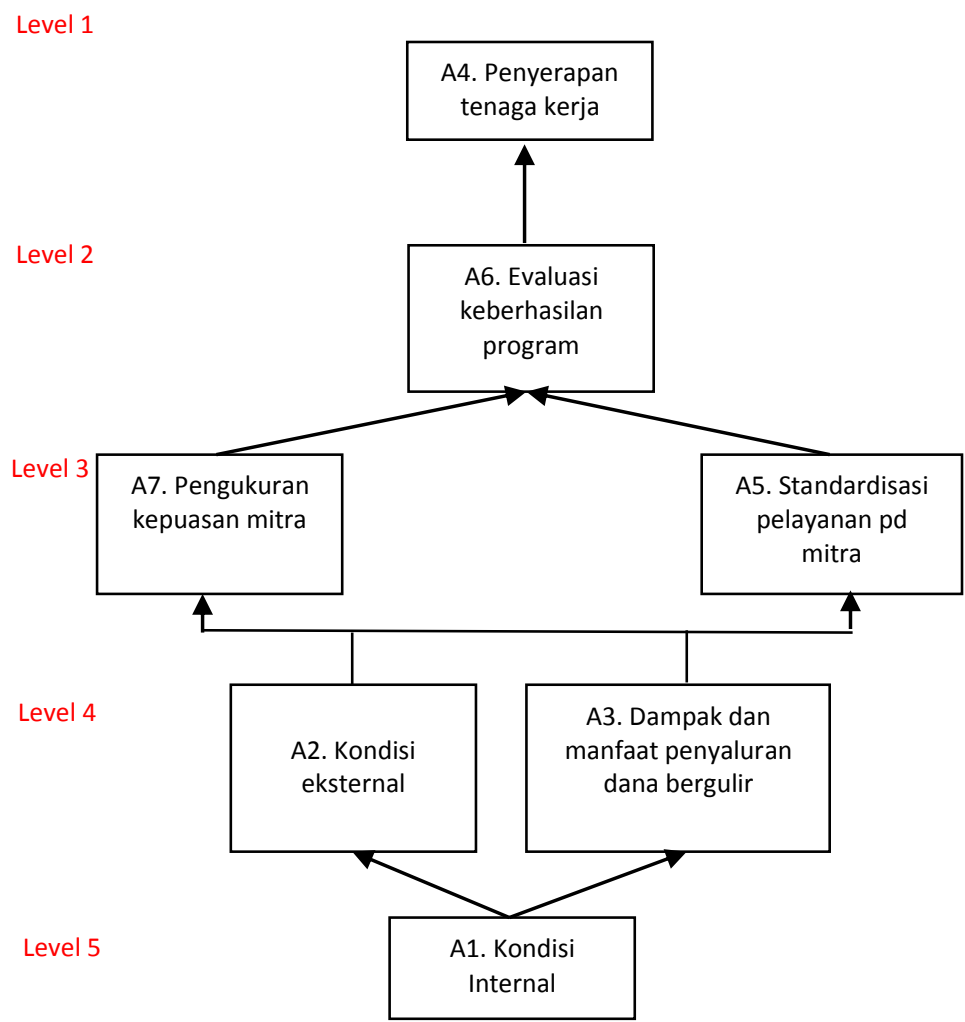

\section{Gambar 2. Model Struktur Elemen} Aspek Kebutuhan

Gambar di atas menunjukkan urutan tahap kebutuhan dalam penerapan strategi pengembangan LPDB Syariah di Indonesia untuk meningkatkan UMKM. Level paling terakhir yakni level 5 merupakan sub-elemen kunci dari elemen aspek kebutuhan, artinya kondisi internal LPDB yang positif memiliki pengaruh paling besar dalam menerapkan strategi pengembangan LPDB Syariah di Indonesia ke depan. Maka diharapkan jika adanya dukungan yang kuat untuk improvement kondisi internal menjadi lebih optimal maka dapat mengenerate variabel pada level yang di atasnya. Melalui level 4 yakni kondisi eksternal yang menunjang dan dampak penyaluran dana bergulir yang efektif maka diharapkan mampu meningkatkan kepuasan para mitra yang 
bekerjasama (level 3). Tentu saja dengan standardisasi pelayanan kepada mitra dan calon mitra yang lebih tepat, presisif dan applicable. Melalui level ini diharapkan dapat mengevaluasi keberhasilan demikian juga kegagalan program yang sudah berjalan (level 2) dan akhirnya tujuan penyerapan tenaga kerja pun dapat tercapai dengan baik dan efektif (level 1).

\section{Elemen Masalah yang Dihadapi}

Elemen masalah yang mungkin dihadapi dalam kerangka pengembangan LPDB Syariah di Indonesia untuk meningkatkan UMKM dijabarkan dalam 5 (lima) sub-elemen sebagai berikut: (A1) Dukungan UU dan kebijakan pemerintah, (A2) Persaingan/kompetisi dengan lembaga keuangan lain, (A3) Kondisi perekonomian domestik dan luar negeri, (A4) Perkembangan sosial, politik dan budaya, serta (A5) Perkembangan dan perubahan teknologi.

Hasil pengolahan ISM menunjukkan urutan masalah yang mungkin dihadapi dalam pengembangan LPDB Syariah di Indonesia untuk meningkatkan UMKM. Secara umum ada 3 level sub-elemen. Pertama adalah adanya kemungkinan perubahan teknologi. Seperti kita ketahui saat ini perubahan teknologi mampu merubah kondisi persaingan pasar dan bisnis secara umum. Yang lainnya adalah kondisi ekonomi domestik dan LN yang mendukung (level 3). Level selanjutnya yang juga penting adalah perkembangan sosial-politik-budaya dan dukungan pemerintah berikut UU yang men-support pengembangan LPDB (level 2). Terakhir namun tidak kalah penting adalah kompetisi dan tingkat persaingan dengan institusi lain yang sejenis, misal perbankan dan lembaga keuangan lain (level 1).

\section{Elemen Perubahan yang}

\section{Dimungkinkan}

$\begin{array}{ccr}\text { Elemen } & \text { perubahan } & \text { yang } \\ \text { dimungkinkan } & \text { dalam } & \text { strategi } \\ \text { pengembangan } & \text { LPDB } & \text { Syariah di }\end{array}$
Indonesia untuk meningkatkan UMKM dijabarkan dalam 7 (tujuh) sub-elemen sebagai berikut: (A1) Proses seleksi terhadap calon mitra yang lebih baik, (A2) Peningkatan kompetensi karyawan, khususnya dalam bidang analisa kredit dan manajemen risiko, (A3) Optimalisasi monitoring dan evaluasi pasca penyaluran pembiayaan, (A4) Kerjasama dengan perguruan tinggi dan universitas di Indonesia dalam kerangka capacity building, (A5) Kerjasama dengan dinas koperasi-UKM di daerah-daerah untuk satuan tugas monitoring, (A6) Identifikasi masalah di lapangan dalam mencari solusi terhadap mitra, dan (A7) Penyelesaian melalui mekanisme PUPN apabila ada sengketa.

Hasil pengolahan ISM menunjukkan urutan tahap perubahan yang dimungkinkan dalam penerapan strategi pengembangan LPDB Syariah di Indonesia untuk meningkatkan UMKM. Level paling terakhir yakni level 4 merupakan sub-elemen kunci dari elemen perubahan yang dimungkinkan, yaitu identifikasi masalah di lapangan dalam mencari solusi terhadap mitra dan proses seleksi terhadap calon mitra yang lebih baik. Selanjutnya level 3 adalah peningkatan kompetensi karyawan khususnya dalam bidang analisa kredit dan manajemen risiko diikuti kerjasama dengan perguruan tinggi dalam pembangunan kapasitas SDM. Dari sini level perubahan dimungkinkan 
selanjutnya adalah optimalisasi monev pasca penyaluran pembiayaan dan kerjasama dengan dinas terkait di daerah untuk satgas monitoring (level 2). Terakhir namun tidak kalah penting adalah penyelesaian melalui mekanisme PUPN (level 1)

\section{KESIMPULAN DAN IMPLIKASI}

Perlu ada strategi pengembangan LPDB syariah di Indonesia agar dapat mengoptimalkan perannya dalam meningkatkan sektor UMKM di Indonesia. Penelitian ini mencoba untuk mengurai sub elemen kunci agar strategi pengembangan LPDB syariah dapat berjalan secara optimal. Hasil penelitian ini memberikan beberapa kesimpulan diantaranya adalah: (1) Elemen aspek kebutuhan yang menjadi kunci utama dalam strategi pengembangan LPDB syariah di Indonesia untuk meningkatkan UMKM adalah perlu adanya dukungan yang kuat agar kondisi internal mampu berjalan secara efektif; (2) Elemen perubahan yang dimungkinkan yang menjadi kunci utama dalam strategi pengembangan LPDB syariah di Indonesia untuk meningkatkan UMKM adalah identifikasi masalah di lapangan dalam mencari solusi terhadap mitra dan proses seleksi terhadap calon mitra yang lebih baik; (3) Elemen masalah yang mungkin dihadapi dalam kerangka strategi pengembangan LPDB syariah di Indonesia untuk meningkatkan UMKM adalah perubahan teknologi dalam struktur ekonomi dan bisnis secara umum.

Berdasarkan hasil penelitian ini, maka berikut beberapa rekomendasi yang dapat peneliti berikan kepada para stakeholders LPDB syariah dan KemenkopUKM secara umum diantaranya adalah diperlukan adanya koordinasi dan kerjasama antara seluruh pemangku kebijakan dan pelaku LPDB syariah dalam mewujudkan LPDB syariah yang memilki dukungan hukum yang kuat, profitable, dan menjadi lembaga pembiayaan alternatif bagi masyarakat dengan ekonomi kelas bawah (unbankable people). Sektor UMKM merupakan salah satu sector usaha yang dominan di Indonesia sehingga perlu didukung melalui aspek permodalan yang kuat. Perbaikan yang berkelanjutan tidak hanya dituntut bagi manajemen koperasi sebagai mitra akan tetapi juga bagi seluruh anggota koperasi. Anggota koperasi juga membutuhkan pelatihan dan pendidikan untuk menambah skill berbisnis, serta kemampuan dan pemahaman dalam hal penerapan prinsip-prinsip syariah.

\section{DAFTAR PUSTAKA}

Akanji, 0.0 (2007). Micro Finance as A Strategy for Poverty Reduction. CBN Economic and Financial Review. Vol.39 No.4.

Ascarya, Widyo G, Widodo C, Enny A, dan Ferry S, 2012. Strategi Meningkatkan Preferensi Perbankan Syariah Indonesia Dalam Menggunakan Pembiayaan BagiHasil. Jakarta: Central Banking Education and Studies Department, Bank Indonesia.

Aslichan, Hubeis M, Sailah I. 2009. Kajian Penilaian Kesehatan dalam Rangka Mengevaluasi Kinerja Lembaga Keuangan Mikro Syariah Baitul Maal 
wat Tamwil, Jurnal Manajemen Pengembangan Industri Kecil Menengah Sekolah Pascasarjana IPB, 4(2), pp.195-205.

Banerjee, Abhijit V., Timothy Besley and Thimothy W. Guinnane (1994). Thy Neighbor's Keeper: The Design of a Credit Cooperative with Theory and a Test. Quarterly Journal of Economics 109(2), 491-515.

Bank Indonesia,2015, Profil Bisnis Usaha Mikro, Kecil dan Menengah, Jakarta

Baskara Kajeng, 2013, Lembaga Keuangan Mikro di Indonesia, Jurnal bulletin Studi Ekonomi, Vol.18,No 2

Berita Negara Republik Indonesia,2017 Peraturan Kemek-kum No 08/Per/M.Kum/VII/2017

Bhattacharya, S., and Momaya, K. (2009). Interpretive Structural Modeling of Growth Enablers in Construction Companies. Singapore Management Review. ABI/INFORM Global: 73

Bolanos et.al. (2005). Using Interpretive Structural Modelling in Strategic Decision-Making Groups. Management Decision 43 (6): 877895.

Devi, Abrista and Rusydiana, Aam Slamet (2016), "Islamic Group Lending Model (GLM) and Financial Inclusion", International Journal of Islamic Business Ethics Vol. 1 No 1, pp. 80-94.

Fukuyama, Francis (2002). Social Capital and Development: The Coming Agenda. SAIS Review Vol. XXII No.1 (winter u/2013 spring 2002)

Gema PKK, (2003). Kemiskinan dan Keuangan Mikro. KPK

Gorvett, R. and Liu, N., 2007. Using interpretive structural modeling to identify and quantify interactive risks. Orlando - USA: ASTIN Colloquium.

Kanungo S dan V.V. Batnagar, 2002. Beyond Generic Models for Information System Quality: The Use of Interpretative Structural Modelling (ISM). Journal of System Research and Behavior Science. Vol. 19 (2), P 531:549.

Kemas, Danial,2015, Rencana Strategi Bisnis LPDB-KUMKM 2015-2019, Jakarta

Lee, D. M. (2007). Structured Decision Making with Interpretive Structural Modelling (ISM). Canada: Sorach Inc.

Lukman, Syukri., Niki Lukviarman, Harif Amali Rivai, Tafdil Husni, Syafrizal, dan Maruf (2008). Kajian Upaya Penguatan Peran Microbanking dan Pendekatan Pembiayaan Kelompok dalam Rangka Pengembangan UMK di Sumatra Barat. Penelitian atas kerjasama antara Bank Indonesia dan Center for Banking Research Universitas Andalas.

LPDB-KUKM. 2018. Ringkasan Eksekutif Rencana Bisinis dan Anggaran LPDB-KUKM 2018

Marimin. 2004. Pengambilan Keputusan Kreteria Majemuk. Teknik dan Aplikasi. Gramedia Widiasarana Indonesia. Jakarta.

Muhar, 2009. "Kebijakan dan Strategi Pengembangan Lembaga Keuangan Mikro". Jurnal Inovasi Vol. 6 No. 4 Desember 2009.

Otoritas Jasa Keuangan, 2015. Siaran Pers OJK dan Perbankan Syariah Gelar Expo iB Vaganza 2015. Jakarta.

Othman, A, Fatimah K, \& Rosita H, 2013. A Comparative Analysis of the Cooperative, Islamic and Conventional 
Banks in Malaysia. American Journal of Economics 3 (SC): page 184-190. Patten, Richard H, Jay K. Rosengar. (1991). The Development of Rural Banking in Indonesia. San Fransisco: ICS Press.

Radyati, Maria R. Nindita (2012). Keuangan Inklusif Perbankan. Published on Universitas Trisakti. MMCSR \& MMCE. http://www.mmcrusakti.org

Riwajanti, Nur Indah, 2014, Exploring the role of Islamic Microfinance Institution in Poverty Alleviation Thourgh Microenterprises Development, A Case Study of Islamic Financial Cooperative (BMT)in IndonesiaKyoto bulletin of Islamic Area Studies, 7 Marc 2014, pp 49-66

Robinson, MS (2001). The Microfinance Revolution, Sustainable Finance for the Poor. World Bank Economic Review.

Rudjito (2003). Sinergi Kebijakan dalam Mendorong Pertumbuhan Usaha Mikro Kecil dan Menengah. Paper dipresentasikan pada Lokakarya Mendorong Pertumbuhan Usaha Kecil dan Menengah yang Sehat dan Berdaya Saing. Asosiasi Pengusaha Indonesia (APINDO). 12 Desember 2003, Aston Hotel: Jakarta.

Rusydiana, Aam S. (2018a). “Developing Islamic financial technology in Indonesia". Hasanuddin Economics and Business Review, Vol. 2, No 2, pp.143-152.

Rusydiana, Aam S. (2018b). “Aplikasi Interpretive structural modeling untuk strategi pengembangan wakaf tunai di Indonesia", Jurnal Ekonomi dan Bisnis Islam, Vol.4, no.1, pp.1-17.
Rusydiana, Aam S, and Abrista Devi, (2018). "Mengembangkan koperasi syariah di Indonesia: Pendekatan Interpretative Structural Modelling (ISM)". Economica: Jurnal Ekonomi Islam, Vol. 9 No. 1, pp.1-23.

Rusydiana, Aam Slamet and Abrista Devi. (2013). “Challenges in Developing Baitul Maal wat Tamwiil (BMT) in Indonesia using Analytic Network Process (ANP)". Business and Management Quarterly Review 4(2) 51-62

Rusydiana, Aam Slamet and Abrista Devi. (2013b). "Mengurai Masalah dan Solusi Pengembangan Lembaga Keuangan Mikro Syariah (LKMS) di Indonesia: Pendekatan Metode BOCR Analytic Network Process (ANP)". Jurnal Ekonomi dan Bisnis Islami Vol.3 No.1 19-40.

Saipudin, Ahmad dkk, 2017, Strategy Pengembangan Keuangan Mikro Syariah Study kasus pada BMT Tawfin Jakarta

Saxena, J. P. 1992. Hierarchy and Classification of Program Plan Element Using Interpretative Structural Modelling. Systems Practice, Vol. 12 (6), P 651:670

Schurmann, Anna $\mathrm{T}$ dan Heid Bart Johnston (2009). The GroupLending Model and Social Closure: Microcredit, Exclusion, and Health in Bangladesh. J Health Popul Nutr. 27(4): 518-527.

Siswanto. 2009, "Strategi Pengembangan Baitull Maal Wattamwil (BMT) Dalam Memberdayakan Usaha Kecil dan Menengah". Tesis pada Program Pascasarjana Universitas Diponegoro. 
Smolo, Edib. 2007, "Microcrediting in Islam: Islamic Micro-financial Institutions". Paper dipresentasikan pada International Conference on Islamic Banking and Finance, IIUM Malaysia, April 2007.

Stiglitz, Joseph E (1990). Peer Monitoring and Credit Markets. World Bank Economic Review 4(3), 351-366.
Suharto, Saat. 2010, Outlook BMT 2011. Permodalan BMT Center: Jogjakarta. Takkar, J., et.al. (2007). Development of a Balanced Scorecard, An Integrated Approach of Interpretive Sructural Modeling (ISM) and Analytic Network Process (ANP). International Journal of Productivity and Performance Management 56 (1): 25-59. 